Article

\title{
Experimental Determination of Excitation Function Curves through the Measurement of Thick Target Yields in Liquid Targets: The Examples of the ${ }^{68} \mathrm{Zn}(\mathrm{p}, \mathrm{n}){ }^{68} \mathrm{Ga}$ and ${ }^{64} \mathrm{Zn}(\mathrm{p}, \alpha)^{61} \mathrm{Cu}$ Nuclear Reactions
}

\author{
Sergio J. C. do Carmo 1,2,*(D) and Francisco Alves $2,3,4 \mathbb{D}$ \\ 1 ICNAS-Produção, University of Coimbra, Pólo das Ciências da Saúde, Azinhaga de Santa Comba, \\ 3000-548 Coimbra, Portugal \\ 2 CIBIT-Coimbra Institute for Biomedical Imaging and Translational Research, University of Coimbra, \\ Pólo das Ciências da Saúde, Azinhaga de Santa Comba, 3000-548 Coimbra, Portugal; franciscoalves@uc.pt \\ 3 ICNAS-Institute for Nuclear Sciences Applied to Health, University of Coimbra, Pólo das Ciências da Saúde, \\ Azinhaga de Santa Comba, 3000-548 Coimbra, Portugal \\ 4 IPC-Instituto Politécnico de Coimbra, Coimbra Health School, 3046-854 Coimbra, Portugal \\ * Correspondence: sergiocarmo@uc.pt
}

check for updates

Citation: do Carmo, S.J.C.; Alves, F. Experimental Determination of Excitation Function Curves through the Measurement of Thick Target Yields in Liquid Targets: The Examples of the ${ }^{68} \mathrm{Zn}(\mathrm{p}, \mathrm{n})^{68} \mathrm{Ga}$ and ${ }^{64} \mathrm{Zn}(\mathrm{p}, \alpha){ }^{61} \mathrm{Cu}$ Nuclear Reactions. Instruments 2022, 6, 3 .

https://doi.org/10.3390/ instruments6010003

Academic Editor: Antonio Ereditato

Received: 30 November 2021

Accepted: 4 January 2022

Published: 7 January 2022

Publisher's Note: MDPI stays neutral with regard to jurisdictional claims in published maps and institutional affiliations.

Copyright: (c) 2022 by the authors. Licensee MDPI, Basel, Switzerland. This article is an open access article distributed under the terms and conditions of the Creative Commons Attribution (CC BY) license (https:// creativecommons.org/licenses/by/ $4.0 /)$.

\begin{abstract}
The present work describes a method to determine excitation function curves and, therefore, cross-sections, making use of the irradiation of liquid targets at distinct energies in a biomedical cyclotron. The method relies on the derivative of experimentally measured thick target yield curves to determine the corresponding excitation function curves. The technique is presented as a valid and practical alternative to the commonly used activation method combined with the stack monitor technique, whose implementation in liquid targets offers practical difficulties. The working principle is exemplified by presenting the results obtained for the clinically relevant ${ }^{68} \mathrm{Zn}(\mathrm{p}, \mathrm{n})^{68} \mathrm{Ga}$ and the ${ }^{64} \mathrm{Zn}(\mathrm{p}, \alpha){ }^{61} \mathrm{Cu}$ nuclear reactions, obtained though the irradiation of liquid targets containing dissolved natural zinc.
\end{abstract}

Keywords: cyclotron; cross-section; thick target yield; liquid targets

\section{Introduction}

Accurate knowledge of cross-sections is mandatory for the investigation, planning and development of production processes of clinically relevant radioisotopes. Cross-sections are not only fundamental to estimate and maximize the amount of the radioisotope of interest to be produced but also to quantify the undesirable radionuclidic impurities produced through other undesirable nuclear reactions unavoidably occurring simultaneously, either on the target material itself and/or on remaining isotopic impurities [1-5]. The quantification of such quantities is fundamental to optimize production processes and unavoidably relies on the accuracy of cross-sections provided; for instance, in order to determine the most adequate energy range and/or the minimal acceptable enrichment for a given target material [3-5].

As a result, continuous efforts have been spent over the last decades toward the experimental determination of accurate cross-sections [6-8], especially for clinically relevant radioisotopes among other applications of interest, as reported in [9] and recently pointed out in [10] — with most of the cross-sections provided obtained through the well-known stack-foil activation method. Consequently, many methods have been described over the years in order to reduce or even prevent some technical difficulties associated with the technique, with the common goals of improving the beam characterization and reducing the experimental error of the data measured. Accurate knowledge of the primary beam is essential: not only it is important to determine the beam current with precision, but 
an accurate knowledge of the beam energy at any point is also fundamental. A direct measurement of the beam current through a deposited electrical charge must be rigorous (e.g., the suppression of secondary electrons is essential), while, in the meantime, guaranteeing that the beam profile impinging on the measurement device corresponds to the beam crossing the stack. On the other hand, errors in the determination of the initial beam energy and/or in the stopping power of the absorber in the foils result in cumulative inaccuracies when determining the beam energy along the stack. This effect is even more relevant when coupled with difficulties in providing and/or quantifying with precision the thickness of the thin solid foils composing the stack. As a result, efforts have been aimed at determining the initial energy of the impinging ions with improved accuracy [11-15] or at reducing uncertainties related to beam current measurements, usually by using well-known monitor reactions under continuous re-evaluation within the stack monitor [6,9]. Such monitor reactions have also found interest in preventing beam current measurements, as several authors have measured and compared activity ratios from distinct radioisotopes produced simultaneously in monitor foils, or even activity ratios for a single radioisotope within the stack to avoid errors associated with the absolute efficiency calibration of the $\gamma$-spectroscopy system, as described in [11]. Moreover, the unique shape of each monitor reaction was also used as a tool to determine the beam initial energy $[11,15]$.

However, practical difficulties still prevent the production of a wider portfolio of experimentally obtained cross-sections data, as it is not always a simple task to properly mount a stack monitor with several thin and homogenous layers containing the target material of interest, in a solid state, with accurately determined thicknesses. Indeed, target materials can present numerous practical difficulties, such as (i) not being available as a solid, therefore making the construction of a stack impossible [16], (ii) being volatile at room temperature or only when irradiated, (iii) the stability of the target under bombardment, iv) being mechanically difficult to handle in the production of homogenous thin layers and (v) being cost-prohibitive.

In order to prevent such practical difficulties, this work presents an alternative method for the determination of cross-sections of interest. The method relies on the experimental determination of the thick target yield (TTY) at saturation curves, $Y_{\text {sat }}(E)$. Usually, the procedure adopted to estimate radionuclide production relies on calculating the TTY at saturation, deduced from some known cross-sections of the excitation curve of interest [9] though the following relationship:

$$
Y_{\text {sat }}\left(E_{I}\right)=\varphi \omega \frac{N_{A}}{A_{T}} \int_{0}^{E_{I}} \frac{\sigma(E)}{S_{T}(E)} d E
$$

where $E$ is the energy of the impinging ions, $E_{I}$ is the initial energy of the impinging ions, $Y_{\text {sat }}\left(E_{I}\right)$ is the thick target yield at saturation at energy $E_{I}$, which is usually expressed in $\mathrm{MBq} / \mu \mathrm{A}_{\text {sat }}, N_{A}$ is Avogadro's number, $A_{T}$ is the molecular mass of the target material, $\omega$ is the percentage of the target material present in the irradiated target, $\varphi$ is the enrichment of the target material used, $\sigma(E)$ is the cross-section at energy $E$ and $S_{T}(E)$ is the targetstopping power at energy $E$, which is usually expressed in $\mathrm{MeV} . \mathrm{cm}^{2} / \mathrm{g}$. The present work describes the determination of an excitation curve through the experimental measurement of its TTY curve by bombarding the target material of interest with several distinct initial energies, as described in [17-20]. The cross-section $\sigma\left(E_{i}\right)$ at energy $E_{i}$ is then given by

$$
\sigma\left(E_{i}\right)=\frac{A_{T}}{\varphi \omega N_{A}} S_{T}\left(E_{i}\right)\left(\frac{d Y_{\text {sat }}(E)}{d E}\right)_{E_{i}}
$$

Moreover, since a common drawback of the stack monitor technique is the large amount of target material required, since it is usually a cost-prohibitive enriched isotope, the present technique was hereby developed and presented by irradiating liquid targets, since these present the advantage of requiring a very low amount of dissolved target 
material, with the benefit of providing the irradiated target in a more suitable liquid chemical form, while also making use of the technological platform developed over the last few years at the University of Coimbra for the production of radiometals in liquid targets $[3,4,21,22]$. This latter advantage is particularly relevant for radionuclides with short half-lives requiring prompt and simple post-irradiation handling, and also for preparing samples to perform $\gamma$-spectrometry. In addition, the use of liquid targets also demonstrates that the technique presented is particularly useful for cases where the target material is commonly not available in a solid state at room temperature.

The present work hereby exemplifies the principle of the technique developed by presenting the results for the excitation curves of the clinically relevant ${ }^{68} \mathrm{Zn}(\mathrm{p}, \mathrm{n})^{68} \mathrm{Ga}$ and the ${ }^{64} \mathrm{Zn}(\mathrm{p}, \alpha){ }^{61} \mathrm{Cu}$ nuclear reactions. Strangely, despite its clinical relevance, as recently pointed out by the IAEA [23], data for the ${ }^{64} \mathrm{Zn}(\mathrm{p}, \alpha)^{61} \mathrm{Cu}$ reaction are scarce. One should also point out that the method can only be used when it is granted that the radionuclide of interest is produced through only one nuclear reaction in the energy range considered. For instance, as shown later, ${ }^{66} \mathrm{Ga}$ was not considered as it is produced though the proton irradiation of natural zinc through both the ${ }^{66} \mathrm{Zn}(\mathrm{p}, \mathrm{n})^{66} \mathrm{Ga}$ and the ${ }^{67} \mathrm{Zn}(\mathrm{p}, 2 \mathrm{n})^{66} \mathrm{Ga}$ reactions.

\section{Materials and Methods}

Thick target yields were experimentally measured by irradiating a commercial liquid target assembly from a commercial biomedical cyclotron, model 18/9 from IBA (Ion Beam Applications) [24], adapted as previously described [3,4,21], with a constant current in the 5-10 $\mu \mathrm{A}$ range for a few minutes. Since fixed-energy $18 \mathrm{MeV}$ protons were available, the necessary several distinct energies impinging on the liquid target were obtained by using several target windows of different material and/or thicknesses. Alloys were avoided due to their larger uncertainty in terms of stopping power. In order to guarantee that the entire incident beam strikes the target material, the target cavity was completely filled in excess (i.e., with a volume larger than the target cavity), with the overflow connection of the target valve also connected to the collecting vial. Similarly, in order to guarantee that no irradiated target material was lost in the process after the irradiation, the liquid target cavity was washed three times after being purged, from bottom to top, with water in excess, so that the totality of all solutions (the irradiated liquid target and the purges) was completely collected into the collecting vial, either through the normal exit port or the overflow connection. The activities of ${ }^{61} \mathrm{Cu},{ }^{66} \mathrm{Ga}$ and ${ }^{68} \mathrm{Ga}$ from the activated target solution were accessed through $\gamma$ spectrometry using a high-purity germanium detector (HPGe), model GEM30P4-76 from ORTEC (ORTEC, Tennessee, US), calibrated using ${ }^{133} \mathrm{Ba}$ and ${ }^{154} \mathrm{Eu}$ radioactive point-like sources, keeping the dead-times inferior to $4 \%$ during acquisition.

\section{Results}

Figures 1 and 2 present the TTY at saturation experimentally obtained from the proton irradiation of liquid target solutions containing diluted natural zinc in the $10-100 \mathrm{mg} / \mathrm{mL}$ range. Even if no calibration of the incident beam energy was performed in the present work-with the uncertainty in the incident energy therefore increasing as the thickness of the target window increases-Figure 1 shows that the thick target yield of ${ }^{66} \mathrm{Ga}$ begins to sharply increase from about $12.5 \mathrm{MeV}$, a value corresponding to the threshold of the ${ }^{67} \mathrm{Zn}(\mathrm{p}, 2 \mathrm{n}){ }^{66} \mathrm{Zn}$ reaction, to begin to contribute [25], thus confirming that the incident energy is close to the expected $18 \mathrm{MeV}$, as verified under similar experimental conditions in [11]. Identically, the thick target yield curves for the production of ${ }^{61} \mathrm{Cu},{ }^{66} \mathrm{Ga}$ and ${ }^{68} \mathrm{Ga}$ seem to begin at around 6,5 and $4 \mathrm{MeV}$, respectively, which are values that are in agreement with previously reported thresholds for the ${ }^{64} \mathrm{Zn}(\mathrm{p}, \alpha){ }^{61} \mathrm{Cu},{ }^{66} \mathrm{Zn}(\mathrm{p}, \mathrm{n}){ }^{66} \mathrm{Ga}$ and ${ }^{68} \mathrm{Zn}(\mathrm{p}, \mathrm{n}){ }^{68} \mathrm{Ga}$ nuclear reactions [25]. Finally, Figure 1 also enables us to distinguish that the concavity of the thick target yield curves for the production of ${ }^{61} \mathrm{Cu}$ and ${ }^{68} \mathrm{Ga}$ changes at around $14 \mathrm{MeV}$ and $11 \mathrm{MeV}$, respectively, also corresponding to the expected maximum values of their excitation curves by taking into account the experimental results of previous works presented in Figures 3 and 4. 


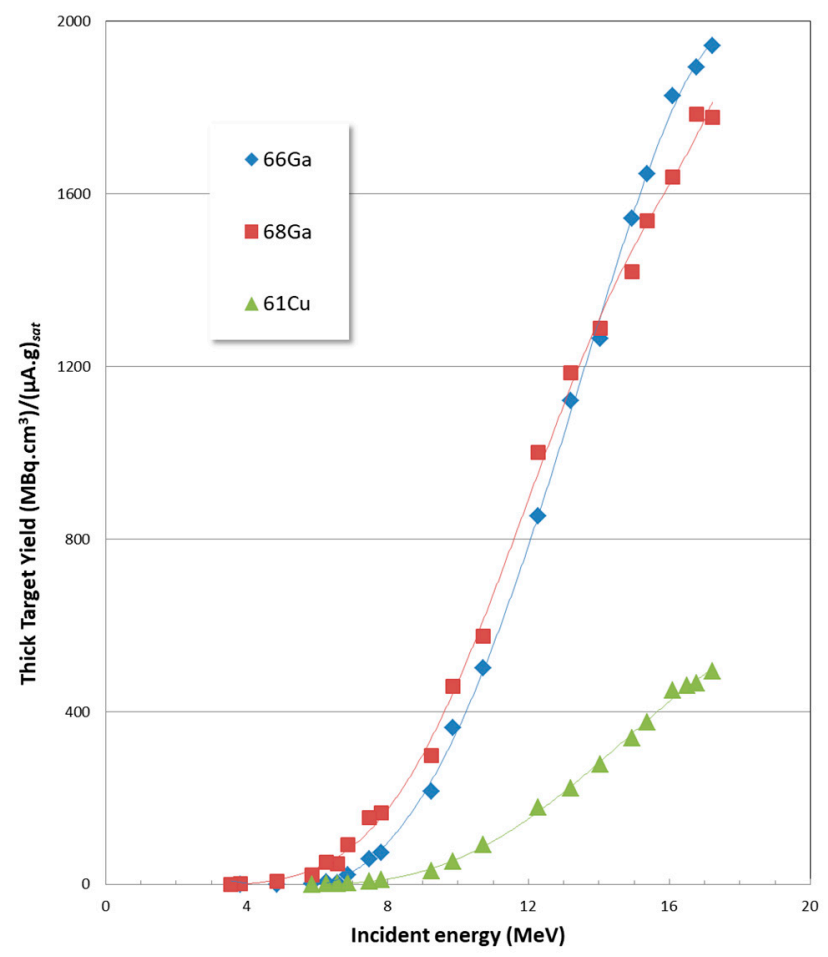

Figure 1. Experimentally measured thick target yields at saturation for the production of ${ }^{61} \mathrm{Cu},{ }^{66} \mathrm{Ga}$ and ${ }^{68} \mathrm{Ga}$ from the proton irradiation of liquid targets containing dissolved natural zinc.

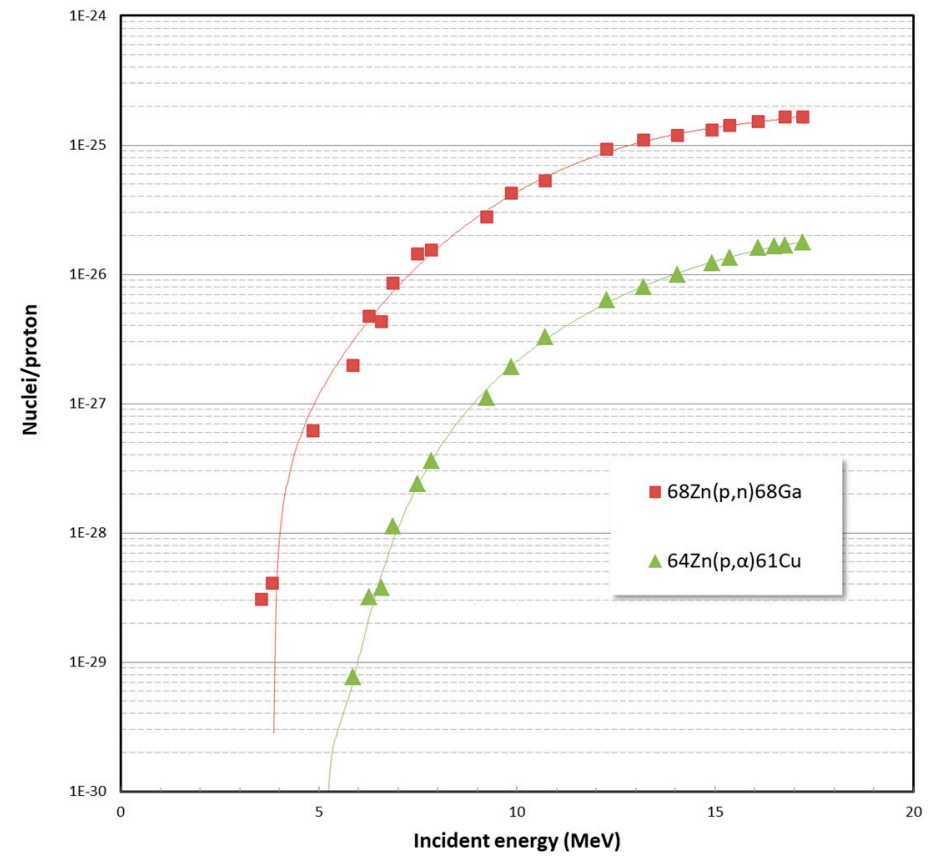

Figure 2. Experimentally measured thick target yields at saturation for the production of ${ }^{61} \mathrm{Cu}$ and ${ }^{68} \mathrm{Ga}$ from the proton irradiation of liquid targets containing dissolved natural zinc.

Since ${ }^{61} \mathrm{Cu}$ and ${ }^{68} \mathrm{Ga}$ are produced by only one nuclear reaction each in the energy range of interest, it is possible to use the obtained TTY curves to determine the respective excitation function curves by using Equation (2), as shown in Figures 3 and 4. On the contrary, the data measured for the production of ${ }^{66} \mathrm{Ga}$ could not be used for the determination of cross-sections. Instead of using Padé approximants, the experimentally obtained TTY curves were fit to polynomial curves to calculate their derivative with ease. 


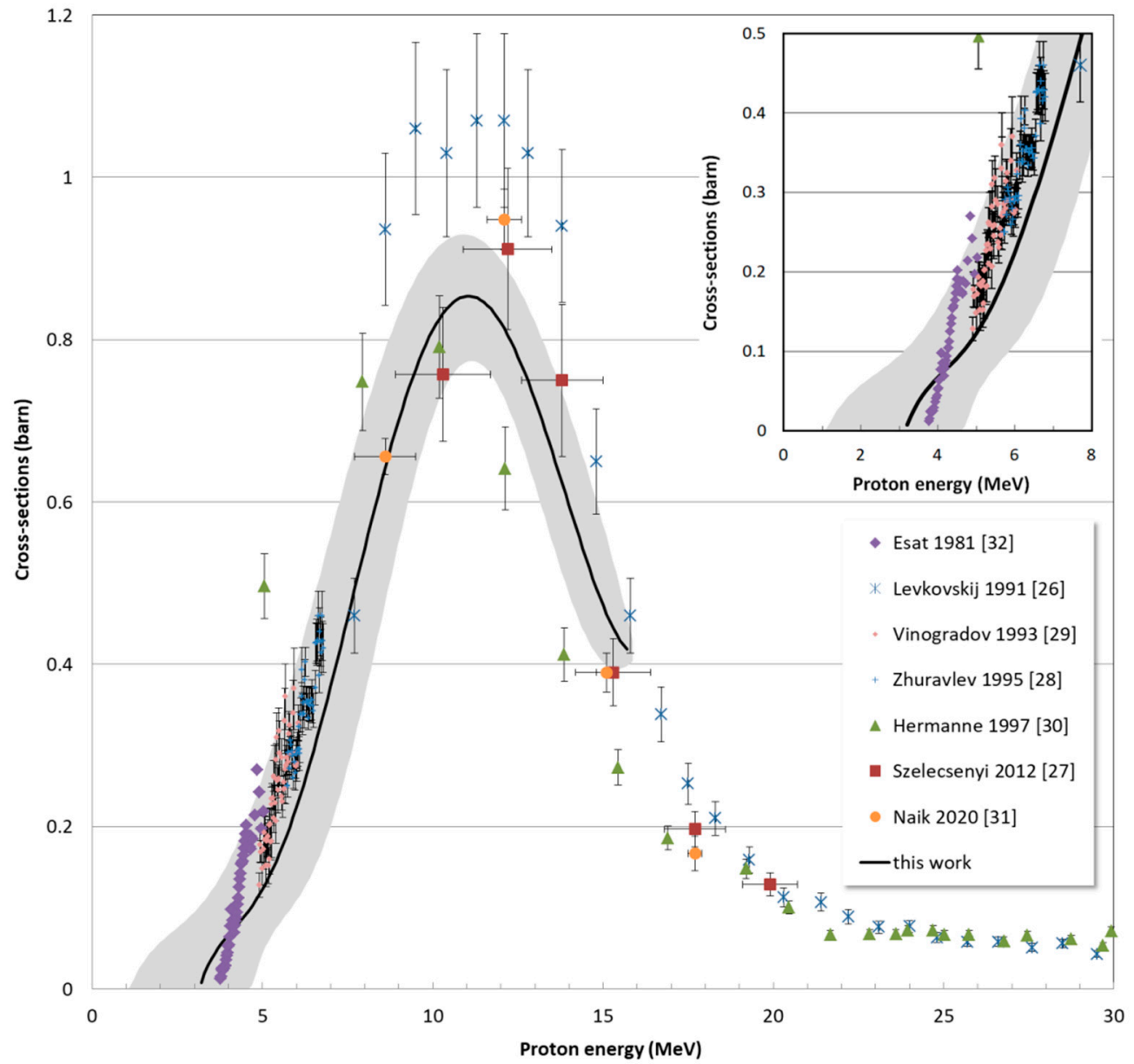

Figure 3. Experimentally deduced excitation function of the ${ }^{68} \mathrm{Zn}(\mathrm{p}, \mathrm{n})^{68} \mathrm{Ga}$ nuclear reaction. The grey area represents the errors in the results presented as the black curve [26-32].

As shown in Figures 3 and 4 , the results of the excitation curves of the ${ }^{68} \mathrm{Zn}(\mathrm{p}, \mathrm{n}){ }^{68} \mathrm{Ga}$ and the ${ }^{64} \mathrm{Zn}(\mathrm{p}, \alpha)^{61} \mathrm{Cu}$ nuclear reactions are shown to be in agreement with previously reported experimental results from several authors. This conclusion is valid for all of the experimental data presented; even for the systematically higher values presented by Levkovskij [26], especially if we take into account the statement from Takacs et al. [6] explaining that the values presented by Levkovskij [26] are systematically $20 \%$ higher than the cross-sections determined by other authors. Such an explanation also partially clarifies how our previously calculated estimations were systematically slightly higher than the produced activities in [4], as the cross-sections provided by Levkovskij [26] were used in these calculations.

The errors in the excitation function curves presented were evaluated, taking into account the uncertainties in the beam current measurement and in the activity measurements. Besides, the errors in the several energies on target were determined considering the uncertainties in the stopping powers $( \pm 5 \%)$ and the cyclotron initial fixed energy $(18 \pm 0.5 \mathrm{MeV})$ - a common limitation with the stack monitor technique, as pointed out in [9] - and therefore spreads as the target foil becomes thicker, meaning that the error in the energy increases for TTY at lower energies, as shown in Figures 3 and 4. 


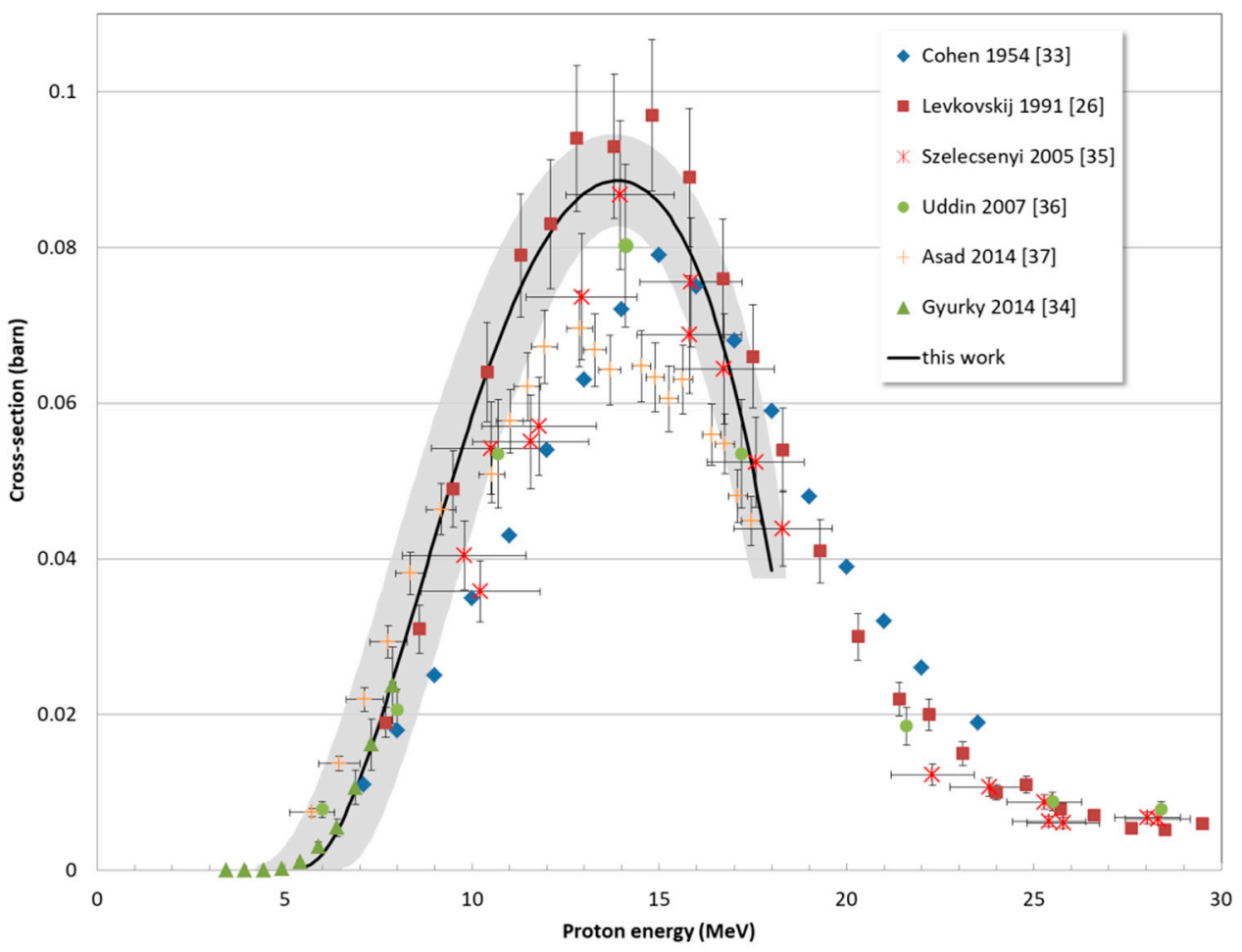

Figure 4. Experimentally deduced excitation function of the ${ }^{64} \mathrm{Zn}(\mathrm{p}, \alpha)^{61} \mathrm{Cu}$ nuclear reaction. The grey area represents the errors in the results presented as the black curve [33-37].

\section{Conclusions}

A methodology based on the cyclotron irradiation of liquid targets is presented for the experimental determination of excitation functions through the experimental measurement of its thick target yield curves. It is presented as a valid alternative with practical advantages, such as requiring a very low amount of the target material, being easier to realize when the stack monitor technique is difficult to implement and enabling measurements of targets in a liquid or gaseous state. The technique is exemplified by presenting results obtained through the irradiation of liquid targets for the clinically relevant ${ }^{68} \mathrm{Zn}(\mathrm{p}, \mathrm{n}){ }^{68} \mathrm{Ga}$ and ${ }^{64} \mathrm{Zn}(\mathrm{p}, \alpha)^{61} \mathrm{Cu}$ nuclear reactions. The good agreement shown with published data testifies for the suitability of the alternative technique presented for the determination of cross-sections.

Author Contributions: Conceptualization, S.J.C.d.C.; methodology, S.J.C.d.C.; formal analysis, S.J.C.d.C.; writing—original draft preparation, S.J.C.d.C.; writing-review and editing, F.A.; supervision, F.A. All authors have read and agreed to the published version of the manuscript.

Funding: This research received no external funding.

Institutional Review Board Statement: Not applicable.

Informed Consent Statement: Not applicable.

Data Availability Statement: Data Sharing not applicable.

Conflicts of Interest: The authors declare no conflict of interest.

\section{References}

1. Qaim, S.M. Development of novel positron emitters for medical applications: Nuclear and radiochemical aspects. Radiochim. Acta 2011, 99, 611-625. [CrossRef]

2. Qaim, S.M.; Scholten, B.; Spahn, I.; Neumair, B. Positron-emitting radionuclides for appliactions, with special emphasis on their production methodologies for medical use. Radiochim. Acta 2019, 107, 1011-1026. [CrossRef]

3. Alves, F.; Alves, V.H.; Neves, A.C.B.; do Carmo, S.J.C.; Natergal, B.; Hellas, V.; Kral, E.; Gonçalves-Gameiro, C.; Abrunhosa, A.J. Cyclotron production of Ga-68 for human use from liquid targets: From theory to practice. AIP Conf. Proc. 2017, 1845, 020001. 
4. Alves, F.; Alves, V.H.; do Carmo, S.J.C.; Neves, A.C.B.; Silva, M.; Abrunhosa, A.J. Production of copper-64 and gallium-68 with a medical cyclotron using liquid targets. Mod. Phys. Lett. A 2017, 32, 1740013. [CrossRef]

5. European Pharmacopeia. Gallium (68Ga) Chloride (Accelerador-Produced) Solution for Radiolabelling. Available online: http:/ / radiofarmacia.org/wp-content/uploads/2018/10/MONOGRAF\%C3\%8DA-GA68Cl.pdf (accessed on 2 May 2019).

6. Takacs, S.; Tarkanyi, F.; Sonck, M.; Hermanne, A. Investigation of the ${ }^{\text {nat }} \mathrm{Mo}(\mathrm{p}, \mathrm{x})^{96 \mathrm{mg}} \mathrm{Tc}$ nuclear reaction to monitor proton beams: New measurements and consequences on the earlier reported data. Nucl. Instr. Methods B 2002, 198, 183-196. [CrossRef]

7. Takacs, S.; Tarkanyi, F.; Hermanne, A.; Paviotti de Corcuera, R. Validation and upgrading of the recommended cross section data of charged particle reactions used for production of PET radioisotopes. Nucl. Instr. Methods B 2003, 211, 169-189. [CrossRef]

8. Qaim, S.M.; Hussain, M.; Spahn, I.; Neumaier, B. Continuing Nuclear Data Research for Production of Accelerator-Based Novel Radionuclides for Medical Use: A Mini-Review. Front. Phys. 2021, 9, 639290. [CrossRef]

9. IAEA-TECDOC-1211, Charged Particle Cross-Section Database for Medical Radioisotope Production: Diagnostic Radioisotopes and Monitor Reactions. Available online: https://www-pub.iaea.org/MTCD/Publications/PDF/te_1211_prn.pdf (accessed on 27 May 2021).

10. Hermanne, A.; Ignatyuk, A.V.; Capote, R.; Carlson, B.V.; Engle, J.W.; Kellett, M.A.; Kidedi, T.; Kim, G.; Hussain, M.; Lebeda, O.; et al. Reference cross sections for charged-particle monitor reactions. Nuclear Data Sheets 2018, 148, 338-382. [CrossRef]

11. do Carmo, S.J.C.; de Oliveira, P.M.; Alves, F. Simple, Immediate and Calibration-Free Cyclotron Proton Beam Energy Determination Using Commercial Targets. Instruments 2019, 3, 20. [CrossRef]

12. Campajola, L.; Braccini, S.; Casolaro, P.; de Luca, D.; Ereditato, A.; Haffner, P.D.; Scampoli, P. Measurement of the proton beam energy of a medical cyclotron based on Rutherford Back-scattering Analysis. Nucl. Instr. Methods B 2019, 440, 114-117. [CrossRef]

13. Nesteruk, K.P.; Ramseyer, L.; Carzaniga, T.S.; Braccini, S. Measurement of the beam energy distribution of a medical cyclotron with a multi-leaf farady cup. Instruments 2019, 3, 4. [CrossRef]

14. Haffner, P.; Aguilar, C.B.; Braccini, S.; Scampoli, P.; Thonet, P.A. Study of the extracted beam energy as a function of operational parameters of a medical cyclotron. Instruments 2019, 3, 63. [CrossRef]

15. Gagnon, K.; Jensen, M.; Thisgaard, H.; Publicover, J.; Lapi, S.; McQuarrie, S.A.; Ruth, T.J. A new and simple calibrationindependent method for measuring the beam energy of a cyclotron. Appl. Radiat. Isot. 2011, 69, 247-253. [CrossRef] [PubMed]

16. Tarkanyi, F.; Qaim, S.M.; Stocklin, G. Excitation functions of $3 \mathrm{He}-$ and $\alpha$-particle induced Nuclear reactions on natural krypton: Production of ${ }^{82} \mathrm{Sr}$ at a compact cyclotron. Appl. Radiat. Isot. 1988, 39, 135-143. [CrossRef]

17. Gyurky, G.; Vakulenko, M.; Fulop, Z.; Halasz, Z.; Kiss, G.G.; Somorjai, E.; Szucs, T. Cross section and reaction rate of the 92Mo(p, $\gamma) 93 \mathrm{Tc}$ determined from thick target yield measurements. Nucl. Phys. A 2014, 922, 112-115. [CrossRef]

18. Basbas, G.; Brandt, W.; Laubert, R. Universal Cross Sections for K-Shell Ionization by Heavy Charged Particles. I. Low Particle Velocities. Phys. Rev. A 1973, 7, 983. [CrossRef]

19. do Carmo, S.J.C.; Borges, F.I.G.M.; Trindade, A.M.F.; Conde, C.A.N. K X-ray production cross sections in Aluminium for 15 keV, $20 \mathrm{keV}$ and $25 \mathrm{keV}$ protons. Nucl. Instr. Methods B 2012, 293, 16-20. [CrossRef]

20. Rashiduzzaman Khan, M.; Crumpton, D.; Francois, P.E. Proton-induced X-ray production in titanium, nickel, copper, molybdenum and silver. J. Phys. B 2001, 9, 455-460. [CrossRef]

21. do Carmo, S.J.C.; Alves, V.H.P.; Alves, F.; Abrunhosa, A.J. Fast and cost-effective cyclotron production of ${ }^{61} \mathrm{Cu}$ using a ${ }^{\text {nat }} \mathrm{Zn}$ liquid target: An opportunity for radiopharmaceutical production and R\&D. Dalton Trans. 2017, 46, 14556-14560.

22. do Carmo, S.J.C.; Scott, P.J.H.; Alves, F. The production of radiometals in liquid targets. EJNMMI Radiopharm. Chem. 2020, 5, 1-21. [CrossRef]

23. IAEA-TECDOC-1955. Production of Emerging Radionuclides towards Theranostic Applications: Copper-61, Scandium-43 and -44, and Yttrium-86; International Atomic Energy Agency: Vienna, Austria, 2021. Available online: https://www-pub.iaea.org/MTCD/ Publications/PDF/TE-1955web.pdf (accessed on 29 November 2022).

24. Courtyn, J.; Devillet, F.; Geets, J.-M.; Ghyoot, M.; Kral, E.; Michaux, O.; Mooij, R.; Nactergal, B.; Nuttens, V.; Perk, L. Performance of IBA New Conical Shaped Niobium [18O] Water Targets. Proceedings of Cyclotrons 2013, Vancouver, BC, Canada. 2013. Available online: https:/ /accelconf.web.cern.ch/CYCLOTRONS2013/papers/wepsh043.pdf (accessed on 12 May 2021).

25. Experimental Nuclear Reaction Data (EXFOR) Database Version of 2021-05-18. Available online: https://www-nds.iaea.org/ exfor/ (accessed on 21 May 2021).

26. Levkovskij, V.N. Activation Cross Section Nuclides of Average Masses (A = 40-100) by Protons and Alpha-Particles with Average Energies $(\mathrm{E}=10-50 \mathrm{MeV})$. 1991. Available online: https:/ /www-nds.iaea.org/CRP-CP-monitor/2RCM/Hussain-2RCM-2014.pdf (accessed on 29 November 2022).

27. Szelecseny, F.; Kovacs, Z.; Nagatsu, K.; Fukumura, K.; Suzuki, K.; Mukai, K. Investigation of direct production of 68 Ga with low energy multiparticle accelerator. Radiochim. Acta 2012, 100, 5-11. [CrossRef]

28. Zhuravlev, Y.Y.; Zarubin, P.P.; Zeic, Y.V.; Kolozhvari, A.A.; Chelgunov, I.V. Excitation functions of (p,n) reactions on nuclei of isotopes Zn from $\mathrm{E}(\mathrm{p})=5.6$ To 6.8 MeV. J. Izv. Rossiiskoi Akademii Nauk Ser. Fiz. 1995, 59, 118. (EXFOR entry A0550:1).

29. Vinogradov, V.M.; Zhuravlev, Y.Y.; Zarubin, P.P.; Kolozhvari, A.A.; Sergeev, V.O.; Sitnikova, I.V. Excitation functions of (p,n) reactions on zinc isotopes in the range of $\mathrm{E}(\mathrm{p})$ from 4.9 to $5.9 \mathrm{MeV}$. J. Izv. Rossiiskoi Akademii Nauk Ser. Fiz. 1993, 57, 154. (EXFOR entry A0841:1).

30. Hermanne, A. Evaluated cross section and thick target yield data of $\mathrm{Zn}+\mathrm{P}$ processes for practical applications. 1997. Private communication for EXFOR entry D4093. 
31. Naik, H.; Suryanarayana, S.V.; Murali, M.S.R.; Noy, K. Excitation function of $68 \mathrm{Zn}(\mathrm{p}, \mathrm{n}) 68 \mathrm{Ga}$ reaction for the production of $68 \mathrm{Ga}$. J. Radioanal. Nucl. Chem. 2020, 324, 285-289. [CrossRef]

32. Esat, M.T.; Spear, R.H.; Zyskind, J.L.; Shapiro, M.H.; Fowler, W.A.; Davidson, J.M. Test of global Hauser-Feshbach calculations for proton-induced reactions on ${ }^{68} \mathrm{Zn}$. Phys. Rev. C 1981, 23, 1822-1825. [CrossRef]

33. Cohen, B.L.; Newman, E.; Charpie, R.A.; Handley, T.H. (p,pn) and (p, $\alpha$ n) Excitation Functions. Phys. Rev. 1954, 94, 620-625. [CrossRef]

34. Gyurky, G.; Fulop, Z.; Halasz, Z.; Kiss, G.G.; Szucs, T. Direct study of the $\alpha$-nucleus optical potential at astrophysical energies using the 64Zn( p, $\alpha) 61 \mathrm{Cu}$ Reaction. Phys. Rev. C 2014, 90, 052801(R). [CrossRef]

35. Szelecsenyi, F.; Kovcs, Z.; Suzuki, K.; Okada, K.; van der Walt, T.N.; Steyn, G.F.; Mukherjee, S. Production possibility of ${ }^{61}$ Cu using proton induced nuclear reactions on zinc for PET studies. J. Radioanal. Nucl. Chem. 2005, 263, 539-546. [CrossRef]

36. Uddin, M.S.; Khandaker, M.U.; Kim, K.S.; Lee, Y.S.; Kim, G.N. Excitation functions of the proton induced nuclear reactions on ${ }^{n a t} \mathrm{Zn}$ up to $40 \mathrm{MeV}$. Nucl. Instrum. Methods B 2007, 258, 313-320. [CrossRef]

37. Asad, A.H.; Chan, S.; Morandeau, L.; Cryer, D.; Smith, S.V.; Price, R.I. Excitation functions of nat $\mathrm{Zn}(\mathrm{p}, \mathrm{x})$ nuclear reactions with proton beam energy below $18 \mathrm{MeV}$. Appl. Radiat. Isot. 2014, 94, 67. [CrossRef] [PubMed] 